\title{
Retraction Note to: Structural and electrochemical impedance spectroscopic studies on reactive magnetron sputtered titanium oxynitride (TiON) thin films
}

\author{
P. Padmavathy ${ }^{1} \cdot$ R. Ananthakumar ${ }^{2} \cdot$ B. Subramanian ${ }^{2} \cdot$ C. Ravidhas ${ }^{1} \cdot$ M. Jayachandran ${ }^{2}$
}

Published online: 24 November 2021

(c) Springer Nature B.V. 2021

Retraction to: Journal of Applied Electrochemistry
(2011) 41:751-756
https://doi.org/10.1007/s10800-011-0294-z

The Editor in Chief has retracted this article because of similarities with other publications by the same authors. After publication, overlap was detected with figures in articles submitted and published within a close time frame. Specifically, Fig. 1a appears to be very similar to Fig. 1a in both [1] and [2] which are described as a different sample. The authors confirmed that these images were used in error and do not represent the sample described in the figure legend. Therefore the data presented in this article is unreliable.

Authors B. Subramanian and R. Ananthakumar agree to this retraction. Authors C. Ravidhas and M. Jayachandran have not responded to any correspondence from the editor or publisher about this retraction. The editor was not able to obtain a current email address for Author P. Padmavathy.

\section{References}

1. Subramanian B, Ananthakumar R, Vidhya VS, Jayachandran M (2011) Influence of substrate temperature on the materials properties of reactive DC magnetron sputtered Ti/TiN multilayered thin films. Mater Sci Eng B 176(1):1-7. https://doi.org/10.1016/j. mseb.2010.08.004

2. Subramanian B, Muraleedharan CV, Ananthakumar R, Jayachandran M (2011) A comparative study of titanium nitride (TiN), titanium oxy nitride ( $\mathrm{TiON}$ ) and titanium aluminum nitride (TiAlN), as surface coatings for bio implants. Surf Coat Technol 205(21-22):5014-5020. https://doi.org/10.1016/j.surfcoat.2011. 05.004

Publisher's Note Springer Nature remains neutral with regard to jurisdictional claims in published maps and institutional affiliations.

The original article can be found online at https://doi.org/10.1007/ s10800-011-0294-z.

B. Subramanian

subramanianb3@gmail.com

1 Department of Physics, Bishop Heber College (Autonomous), Tiruchirappalli 620 017, India

2 CSIR-Central Electrochemical Research Institute, Karaikudi 630 006, India 